\title{
ESTUDO FITOQUÍMICO, ATIVIDADE ANTIOXIDANTE E INIBIÇÃO DA ENZIMA LIPASE PANCREÁTICA DE EXTRATO DO FRUTO DO Pithecellobium dulce ORIUNDO DO SEMIÁRIDO BRASILEIRO
}

\author{
Haryel Lima Santos ${ }^{1}$; Alexsandro Branco ${ }^{2}$ \\ 1. Bolsista PROBIC/UEFS, Graduando em Farmácia, Universidade Estadual de Feira de Santana, e-mail: \\ haryellima@gmail.com \\ 2. Orientador, Departamento de Saúde, Universidade Estadual de Feira de Santana, e-mail: branco@uefs.br
}

PALAVRAS-CHAVE: Atividade antioxidante; Lipase pancreática; Pithecellobium dulce.

\section{INTRODUÇÃO}

A introdução de alimentos funcionais na dieta humana pode proporcionar benefícios para a saúde, principalmente no início do desenvolvimento e crescimento, regulação de processos metabólicos, defesa contra o estresse oxidativo, benefícios cardiovasculares, fisiologia gastrointestinal e desempenho mental, cognitivo e físico.

Da família das Fabaceaes, a Pithecellobium dulce (Roxb.) Benth é uma espécie popularmente conhecida como ingá-doce, guamã-americano ou guamúchil. Árvore de porte médio pode atingir até $10 \mathrm{~m}$ de altura e encontra-se distribuída em diversas partes do mundo, sobretudo, nos trópicos americanos (LORENZI et al., 2003; MALIK et al., 2010). Suas vagens frescas contem cerca de $50 \%$ de polpa, cuja composição é rica em proteínas, carboidratos, fibras, além de excelente fonte de vitaminas e minerais, podendo ser utilizada na alimentação animal (MALIK et al., 2010).

A inibição da lipase pancreática está estreitamente ligada à diminuição da absorção de lipídeos e controle dos efeitos nocivos, enquanto que os antioxidantes estão relacionados à diminuição de radicais livres no organismo. Antioxidantes naturais podem ser adquiridos pela ingestão de alimentos que contenham, por exemplo, $a$-tocoferol (vitamina- E), $\beta$-caroteno (pro-vitamina-A), ácido ascórbico (vitamina- C), e compostos fenólicos, onde se destacam principalmente os flavonoides e poliflavonoides (BARREIROS; DAVID; DAVID, 2006).

A ingestão de frutos já está ligada a uma boa qualidade de vida, devido à riqueza de fibras e nutrientes, contudo a determinação da associação de frutos com o metabolismo de lipídios e com atividade antioxidante poderá ser uma medida de profilaxia de fácil uso pela população, sendo assim, o presente trabalho tem por objetivo avaliar a atividade antioxidante e inibitória da lipase pancreática do extrato do fruto de Pithecellobium dulce (Fabaceae).

\section{METODOLOGIA}

\section{Coleta do material}

Os frutos foram coletados na cidade de Ruy Barbosa- BA, identificados por um botânico do Herbário da Universidade Estadual de Feira de Santana (HUEFS) e separadas manualmente as cascas e as polpas.

\section{Obtenção dos extratos}

Os frutos foram secos em estufa com temperatura controlada $\left(40^{\circ} \mathrm{C}\right)$ e moídas em moinho de facas (tipo Wiley). Os extratos brutos foram obtidos por maceração do material pulverizado em etanol e água $\left(\mathrm{EtOH} / \mathrm{H}_{2} \mathrm{O}, 80: 20\right)$, separadamente, por duas extrações consecutivas, de $72 \mathrm{~h}$ cada, e o filtrado obtido em cada etapa reunido e o volume reduzido em rotaevaporador. Os extratos hidroetanólicos foram submetidos a um processo de partição líquido-líquido com solventes. Os extratos brutos foram submetidos à cromatografia em 
coluna aberta recheada com sílica gel e eluída com solventes orgânicos na ordem crescente de polaridade para obtenção das frações.

\section{Ensaio da atividade inibitória da lipase pancreática}

A enzima lipase pancreática suína (tipo II, SIGMA), na concentração de $10 \mathrm{~g} \mathrm{~L}-1$, foi preparada em tampão Tris-HCl 0,05 mol L-1, pH 8,0 (contendo CaCl2 0,010 mol L-1e $\mathrm{NaCl}$ 0,025 mol L-1). Utilizou-se como substrato p-nitrofenilpalmitato na concentração de 0,008 mol L-1, dissolvido em TritonX 100, 0,5\% (p/v). Todas as análises foram feitas em triplicata. Em cada análise, a mistura de reação $(100 \mathrm{~mL}$ de enzima, $50 \mathrm{~mL}$ de água e $50 \mathrm{~mL}$ de substrato) foi incubada por quatro períodos de tempo (10, 20, 30 e $40 \mathrm{~min}$.). Controles sem enzima (branco substrato) e sem substrato (branco enzima) foram incubados do mesmo modo que os tubos experimentais. Determinou-se a absorbância do produto da ação da lipase sobre o pnitrofenolpalmitato (p-nitrofenol) em espectrofotômetro no $\lambda$ de $410 \mathrm{~nm}$. A inclinação da reta do gráfico, Absorbância x Tempo, será calculada e utilizada como referência para $\mathrm{o}$ cálculo da \% inibição da lipase pancreática.

\section{Atividade antioxidante}

Os extratos foram avaliados quanto ao potencial antioxidante pelo Teor de Fenólicos totais (TFT), Avaliação do sequestro do radical livre DPPH• e Avaliação da inibição da Autooxidação do betacaroteno.

\section{Avaliação do teor de fenólicos totais}

As amostras a serem testadas foram preparadas a $100 \mu \mathrm{g} / \mathrm{mL}$ em etanol. Em microplacas de 96 poços foram misturados $20 \mu \mathrm{L}$ do extrato a $100 \mu \mathrm{L}$ do reagente de FolinCiocalteu (1:10) e após 8 minutos foi adicionado $80 \mu \mathrm{L}$ de carbonato de sódio a 7,5\% (p/v). A placa foi incubada em uma câmara escura à temperatura ambiente $\left(25^{\circ} \mathrm{C}\right)$ durante 60 min e em seguida a sua absorbância foi mensurada a $620 \mathrm{~nm}$ utilizando o leitor de microplacas Thermo Scientific ${ }^{\mathrm{TM}}$ Multiskan ${ }^{\mathrm{TM}}$ FC Microplate Photometer contra um branco. A concentração dos polifenois em amostras foi derivada a partir de uma curva de calibração padrão de ácido gálico no intervalo de 10-100 $\mu \mathrm{g} / \mathrm{mL}$. Os dados foram expressos em miligrama de equivalente de ácido gálico (EAG) por grama do extrato seco.

\section{Avaliação do sequestro do radical livre DPPH•}

A atividade antioxidante também foi determinada através da capacidade dos compostos presentes nas amostras $(100 \mu \mathrm{g} / \mathrm{ml})$ em sequestrar o radical estável DPPH $\bullet 40 \mu \mathrm{L}$ das amostras a $160 \mu \mathrm{L}$ de solução etanólica de $\mathrm{DPPH} \bullet(0,2 \mathrm{mM})$. Substâncias padrão (BHT e Ácido Ascórbico - AA) foram testadas como controle positivo. Foi feito um branco para cada concentração de amostra ou padrão testado, substituindo a solução de DPPH• por etanol, e foi feito um controle negativo substituindo as soluções-teste por etanol. As soluções reagentes foram incubadas no escuro a temperatura ambiente durante $30 \mathrm{~min}$ para que a reação ocorresse e a redução do radical livre foi medida através da leitura da absorbância a $517 \mathrm{~nm}$ utilizando o leitor de microplacas Thermo Scientific ${ }^{\mathrm{TM}}$ Multiskan $^{\mathrm{TM}}$ FC Microplate e os resultados foram expressos em Porcentagem de Sequestro do Radical Livre (\%SRL).

\section{Avaliação da Inibição da Auto-oxidação do beta-caroteno}

Uma mistura reacional foi preparada utilizando-se $1 \mathrm{~mL}$ de solução de beta-caroteno (0,2mg/mL em clorofórmio), 20mg de ácido linoleico e 200mg de tween 60 (emulsificador). A mistura foi submetida à completa evaporação do clorofórmio e então adicionada $90 \mathrm{~mL}$ de água destilada, agitando-se vigorosamente para promover a aeração. Amostras a serem testadas foram preparadas a $100 \mu \mathrm{g} / \mathrm{mL}$. Alíquotas de $20 \mu \mathrm{L}$ das amostras e $250 \mu \mathrm{L}$ da mistura 
reacional foram adicionadas à microplaca de 96 poços para a leitura de absorbância em aparelho Thermo Scientific ${ }^{\mathrm{TM}}$ Multiskan ${ }^{\mathrm{TM}}$ FC Microplate Photometer a $470 \mathrm{~nm}$.

\section{Tratamento Estatístico}

As análises foram feitas em triplicata e os resultados foram expressos como média \pm desvio padrão. A significância estatística foi determinada utilizando a análise de variância (ANOVA) seguido do teste de Dunnet. Valores foram considerados significativos com $\mathrm{p}<0,05$. O programa estatístico utilizado foi o Graphpad Prism, versão 5.0.

\section{RESULTADOS E/OU DISCUSSÃO}

\section{Obtenção dos extratos}

A etapa de secagem do material vegetal proporcionou a perda de água, o que promoveu maior estabilidade microbiológica do material, assim como facilidade no processo de trituração. A pulverização realizada possibilitou maior superfície de contato com o solvente extrator na maceração, resultando em um melhor arraste de compostos no procedimento. $\mathrm{O}$ rendimento da extração foi calculado pela razão das massas dos extratos após secagem e suas respectivas massas após a pulverização. O extrato das cascas obteve rendimento de $28,13 \%$ enquanto que o da polpa rendeu $18,49 \%$.

\section{Inibição da lipase pancreática}

O potencial dos extratos em inibir a enzima lipase pancreática foi expresso em porcentagem de Inibição da atividade da Lipase Pancreática (\% ILP). Os extratos apresentaram diferença estatística significativa quando comparados com o controle negativo de acordo com teste de Dunnet ( $\mathrm{p}<0,05$ ). O padrão Orlistat atingiu 88,19\% de ILP, enquanto que o melhor extrato, Pithecellobium dulce casca (EPDUC), obteve 24,48 $\pm 0,56 \%$ de ILP enquanto que a polpa inibiu $11,4 \pm 2,94 \%$ da atividade da enzima.

\section{Atividade antioxidante}

Tabela 1. Atividade antioxidante dos extratos de $P$. Dulce

\begin{tabular}{llll}
\hline & $\begin{array}{l}\text { \%TFT (mg EAG/g } \\
\text { de extrato) }\end{array}$ & \%SRL & \%IAB \\
\hline$P$. Dulce Casca & $68,62 \pm 2,98$ & $34,42 \pm 1,69$ & $29,41 \pm 3,45$ \\
$P$. Dulce Polpa & $50,79 \pm 3.34$ & $22,99 \pm 0,81$ & $14,22 \pm 3,17$ \\
\hline
\end{tabular}

Legenda: Avaliação em porcentagem do potencial antioxidante pelo Teor de Fenólicos totais (TFT), sequestro do radical livre (SRL) e inibição da Auto-oxidação do betacaroteno (IAB).

Os resultados obtidos no teste de teor de fenólicos totais estão resumidos na tabela X. A curva padrão do ácido gálico que embasou os resultados, bem como a equação da reta e o valor do coeficiente de determinação (R2) estão demonstrados na figura X. Os extratos apresentaram diferença estatística significativa quando comparados com o controle negativo de acordo com teste de Dunnet ( $\mathrm{p}<0,05$ ). O extrato que mais se destacou foi o da casca, com $68,62 \pm 2,98 \mathrm{mg}$ EAG/ $\mathrm{g}$ de extrato e a polpa obteve 50,79 $\pm 3.34 \mathrm{mg}$ EAG/ g de extrato. 




Figura 1. Curva padrão do ácido gálico

No teste da avaliação do sequestro do radical $\mathrm{DPPH} \bullet$ o potencial antioxidante foi determinado pela capacidade de cada extrato, na concentração de $100 \mu \mathrm{g} / \mathrm{mL}$, em sequestrar o $\mathrm{DPPH} \bullet$ e os resultados foram expressos em \%SRL (\% Sequestro do Radical Livre). Os resultados das amostras se distinguiram estatisticamente do controle negativo ( $\mathrm{p}<0,05)$, segundo a ANOVA seguida do teste de Dunnett, o que indica a atividade positiva destas no teste. Dentre os extratos, a casca apresentou melhores resultados com 34,42 $\pm 1,69 \%$ SRL enquanto que a polpa conseguiu sequestrar 22,99 $\pm 0,81 \%$ dos radicais. Os controles positivos atingiram 95,60\% SRL e 66,70\% SRL para o Ácido Ascórbico e BHT, respectivamente.

$\mathrm{O}$ teste que avalia a inibição da auto-oxidação do betacaroteno foi realizado e os resultados estão expressos na tabela x. Sabendo-se que há compostos fenólicos nos mesmos, comparouse com flavonóides de atividade antioxidante já conhecida (Quercetina e Rutina). De acordo com o teste de Dunnet, houve diferença estatística significativa entre eles. Essa diferença já era esperada visto que um extrato bruto quando comparado a um padrão isolado terá sua atividade reduzida. Observou-se uma linearidade com o resultado da atividade sequestradora do DPPH•, isso significa dizer que os mesmos extratos mais ativos nos dois testes. $\mathrm{O}$ extrato da casca inibiu 29,41 $\pm 3,45 \%$ da auto-oxidação do Betacaroteno e a polpa inibiu 14,22 $\pm 3,17$ $\%$. Os padrões Quercetina e Rutina inibiram 50,24 $\pm 5,44 \%$ e 41,87 $\pm 3,65 \%$, respectivamente.

\section{CONSIDERAÇÕES FINAIS}

A atividade inibitória da lipase pancreática do extrato do fruto de Pithecellobium dulce (Fabaceae) mostrou-se baixa indicando que os extratos possuem baixo potencial em inibir a enzima. A atividade antioxidante mostrou diferença significativa na etapa do Teor de Fenólicos totais (TFT), detacando-se a casca e a polpa. No teste da avaliação do sequestro do radical DPPH• houve resposta satisfatória, a casca apresentou melhores resultados comparada a polpa. No teste de avaliação da inibição da Auto-oxidação do betacaroteno, o extrato da casca houve maior inibição quanto à polpa. $\mathrm{O}$ extrato da casca apresentou maior conteúdo de compostos fenólicos e foi também o que apresentou melhores resultados nos testes antioxidantes e antiobesidade.

\section{REFERÊNCIAS}

BARREIROS A.L.B.S, DAVID J.M, DAVID J.P. Estresse oxidativo: relação entre geração de espécies reativas e defesa do organismo. Quim Nova. 2006;29 (1):113-23.

LORENZI, H. et al. Árvores Exóticas no Brasil: madeiras, ornamentais e aromáticas. 1.ed. Nova Odessa: Platarum, 2003. 352p.

MALIK, S. K. et al. Genetic resources of tropical underutilized fruits in India. New Delhi: National Bureau of Plant Genetic Resources, 2010. 168 p. 